\title{
LA FORMACIÓN DE UN ESPACIO PÚBLICO PARA LA CIENCIA EN LA AMÉRICA LATINA DURANTE EL SIGLO XIX
}

\author{
Leoncio López-Ocón Cabrera \\ Departamento de Historia de la Ciencia - Centro de Estudios Históricos, CSIC \\ Duque de Medinaceli, 6 - Madrid (España)
}

\section{RESUMEN}

Se muestra cómo durante el siglo XIX se produjo en sectores minoritarios de las sociedades latinoamericanas una interrelación entre oferta y demanda de conocimientos científicos y técnicos que favoreció la creación de un espacio público para la ciencia. La configuración de esa esfera pública, debida a la acción de múltiples soportes divulgativos, tuvo una proyección exterior, como lo prueba la presencia latinoamericana en las exposiciones universales y la existencia de periódicos que facilitaron una comunicación trasatlántica de ideas científico-técnicas.

\section{SUMMARY}

It is shown how the creation of a public sphere for science was encouraged by a supply and demand relationship of scientific and technological knowledge in minoritary sectors of latin american societies in XIXth Century. The shaping of such public domain by multiple popularization tools had an external projection as asserted by Latin America presence in World Exhibitions and periodicals promoting transatlantic flow of scientific and technological ideas.

\section{INTRODUCCIÓN}

En las primeras páginas de Cien años de soledad José Arcadio Buendía, el patriarca de la saga, predice a su esposa Ursula Iguarán que "aquí —es decir en la re-

\footnotetext{
* Este trabajo se ha efectuado en el marco del proyecto de investigación PB 94-003: "Producción de objetos científicos y mundialización de la ciencia", dirigido por Antonio Lafuente. Para su realización ha sido muy importante la consulta de materiales bibliográficos en la Bibliothéque Nationale de Paris, durante el bienio 1993 y 1994, y en la biblioteca del Ibero-Amerikanisches Institut Preussischer Kulturbesitz de Berlin en julio de 1995 y agosto de 1997 gracias a sendas becas de intercambio entre el CSIC y la Deutsche Forschungsgemeinschaft (DFG). El autor desea expresar su agradecimiento por las facilidades que le brindaron a lo largo de su investigación al director de esa institución Dietrich Briesemeister y a los investigadores Alden Dittmann, Oskar Vetter, Peter Masson, Renate Löschner y Günter Vollmer.
} 


\section{LEONCIO LÓPEZ-OCÓN CABRERA}

gión mítica de Macondo, que simboliza Colombia y por extensión la América latina- nos hemos de pudrir sin recibir los beneficios de la ciencia"l. Hasta hace poco tiempo, en efecto, ha sido usual contemplar la América latina como un Macondo científico $^{2}$. Quienes así miraban sostenían que ese área geográfica habría sido marginal y excéntrica respecto a los avances logrados por la ciencia moderna. Esta imagen "macondista" del pasado científico latinoamericano se ha visto además reforzada por la visión de quienes contemplan la ciencia iberoamericana como un desenvolvimiento discontinuo, intermitente, de cimas luminosas y valles oscuros, es decir, como un proceso hecho de momentos estelares que se alternan con los de estancamiento o retroceso, de épocas científicas y de otras anticientíficas. Arguyen los defensores de esta visión que la introducción de los métodos de observación y experimentación, característicos de la scienza nuova, se incorporaron tardíamente en el ámbito cultural iberoamericano en la era moderna, tuvieron un impacto epidérmico en la época de la Ilustración, y hubieron de transcurrir décadas hasta que a principios del siglo XX se crearan instituciones científicas homologables a las del mundo noratlántico ${ }^{3}$.

Pero si adoptamos otra mirada y otros criterios para observar el pasado de la ciencia en la América latina, quizás se pueda matizar la imagen de ese supuesto Macondo científico. Ciertamente la América latina no ha producido apenas Premios Nobel, ni en su seno se han generado numerosos descubrimientos científicos. Pero no es menos cierto que en esa región cultural se han creado instituciones científicas estables y productivas, capaces de llevar a cabo investigaciones básicas y aplicadas, adecuadas a una cierta satisfacción de necesidades locales, o que permitiesen comprender mejor los problemas científicos nacionales. Ha sido precisamente esa capacidad de definir y elegir objetos de estudio en función de factores locales la que ha permitido que esas instituciones arraiguen, y encuentren una "audiencia" y soportes sociales para sus trabajos. Así ha sucedido, por ejemplo, con el Seminario de Minería de México, el Observatorio Astronómico de Bogotá y el Instituto Histórico-Geográfico de Río de Janeiro, instituciones ya bicentenarias o centenarias. Además, diversos casos de excelencia científica que surgieron en la América latina en las primeras décadas del siglo XX, estudiados en los últimos años ${ }^{4}$, pueden ser también entendi-

1 Garcia MARQuez, G. (1967), Cien años de soledad, Buenos Aires, p. 19

2 Ver al respecto PYENSON, L. (1988), "Macondo científico: Instituciones científicas en América latina a principios del siglo XX", en SANCHEZ RON, J.M. (1988), 1907-1987. La Junta para Ampliación de Estudios e Investigaciones Científicas 80 años después, Madrid, vol. I, pp. 229-249 y LOPEZ-OCON, L. (1995), "Discontinuidades y tradiciones en la ciencia iberoamericana", en Cadernos IG/UNICAMP, (Campinas), vol. 5, $\mathrm{n}^{\circ} 1$, pp. 77-84

3 TRABULSE, E. (1991), "Continuidad y discontinuidad de la ciencia mexicana", en Crítica y heterodoxia. Ensayos de historia mexicana, Guadalajara, pp. 113-119

4 Entre esos estudios de caso cabe destacar los emprendidos por STEPAN, N. (1980), Beginnings of Brazilian Science. Oswaldo Cruz, medical research and policy, 1890-1920, New York y CuETO, M. 
dos como el resultado de un largo y complejo proceso histórico latinoamericano, gestado en las postrimerías de la época colonial y desarrollado durante todo el siglo XIX al formarse y consolidarse los Estados nacionales, que hizo posible la acumulación de conocimientos y la creación de un espacio público que, aunque con limitaciones, hizo posible la creación de mecanismos de producción y reproducción de conocimientos y prácticas científicas.

Las páginas que siguen van encaminadas a mostrar cómo se creó y consolidó ese espacio público favorable al desenvolvimiento de las actividades científicas durante las tres grandes etapas que caracterizan la vida intelectual latinoamericana del siglo XIX: la ilustración, el romanticismo y el positivismo. La hipótesis que se va a sostener es que a lo largo de ese siglo se generó una interrelación entre oferta y demanda de conocimientos científicos en sectores minoritarios de las sociedades latinoamericanas, que favoreció un movimiento de "nacionalización" de las actividades científicas en diálogo permanente con las novedades procedentes del mundo exterior. Para desarrollar esta idea-fuerza se seguirá una estrategia doble. Por un lado se delinearán las características de cada una de las etapas de ese proceso de construcción de un espacio público para la ciencia, que se conformó en las sociedades latinoamericanas a lo largo del siglo XIX, y se abordará sucintamente el análisis de algunos de los factores externos que contribuyeron a la configuración de ese interés público por la ciencia, como fueron la existencia de periódicos que facilitaron una comunicación trasatlántica de ideas científico-técnicas, y la participación latinoamericana en las exposiciones universales.

\section{LAS ETAPAS DE UN PROCESO}

A lo largo del siglo XIX proliferaron por toda la América latina mensajeros de la ciencia que, con sus actividades comunicativas, favorecieron la creación y consolidación de un espacio público para la ciencia en esa región cultural. Fueron cinco fundamentalmente los instrumentos usados por esos mensajeros para llevar a cabo su programa de aculturación científica: el uso de la prensa, la creación de un asociacionismo científico y de nuevas instituciones educativas, la fundación de museos de historia natural y la participación en las exposiciones universales.

Debido a su carácter portátil y a su capacidad de desplazamiento por el espacio y por el tiempo, quizás quepa considerar a los medios impresos como los que tuvieron mayor impacto en la creación de un interés social por el desenvolvimiento científico-

(1989), Excelencia científica en la periferia. Actividades científicas e Investigación Biomédica en el Perú 1890-1950, Lima. 
técnico. De ahí que convenga trazar las grandes líneas de desarrollo de un periodismo científico en la América latina del siglo XIX ${ }^{5}$.

Durante los últimos años del siglo XVIII y primera década del siglo XIX apareció en las capitales virreinales (México, Lima, Bogotá y Buenos Aires) un periodismo científico de calidad6. En él se expresaron los representantes de las tres tradiciones científicas generadas por cada una de las tres grandes estructuras de poder político, social y económico presentes en las colonias hispano-americanas: la eclesiástica, la virreinal y la metropolitana ${ }^{7}$. La emergencia de ese periodismo permitió crear una opinión pública interesada en problemas científico-técnicos. Surgió entonces un incipiente espacio público para la ciencia. Tal y como sucediera en Europa a fines del siglo $\mathrm{XVII}^{8}$, en esos periódicos hispanoamericanos los sabios locales comunicaron a sus lectores, formados por gentes instruidas, las "verdades que pudiesen aplicar" en su vida cotidiana.

Esa actividad periodística tuvo una función plural: estimuló la capacidad crítica del público y fue usada como un ariete contra el dominio colonial9 ${ }^{9}$. Desempeñó también un papel cultural y formativo importante. Esos periódicos fueron concebidos como emisarios y mecanismos de transporte de información y saberes. Por ello no ha de extrañar que la Sociedad de Amantes del País de Lima, impulsora del Mercurio Peruano $^{10}$, intentase equiparar su publicación con las actividades del dios Mercurio,

5 Una visión panorámica y más amplia que la que se ofrece aquí se encuentra en LOPEZ-OCON, L. (1996), "Mensajeros de la ciencia en la periferia. La divulgación de los conocimientos científico-técnicos en la América latina durante el siglo XIX a través de la prensa", Región (Cali), n 5, pp. 3-33, que es un desarrollo de la comunicación presentada al IV Congreso Latinoamericano de Historia de las Ciencias y la Tecnología celebrado en Cali entre el 24 y el 27 de enero de 1995 y que fue publicada con el título de "La divulgación científico-técnica en la prensa de América latina durante el siglo XIX: estado de la cuestión y estrategias de investigación", en ARBOLEDA, L.C. y OSORIO, C., eds., (1997), Nacionalismo e internacionalismo en la historia de las ciencias y la tecnología en América latina, Cali, pp. 391-398

6 Ver SALADINO, A. (1996), Ciencia y prensa durante la Ilustración latinoamericana, México

7 LAFUENTE, A. y LOPEZ-OCON, L. (1996), "Tradiciones científicas y expediciones ilustradas en la América hispánica del siglo XVIII", en SALDAÑA, J.J. (1996), Historia social de las ciencias en América latina, México, pp. 247-281

8 HABERMAS, J. (1993), L'espace public. Archéologie de la publicité comme dimension constitutive de la société bourgeoise, Paris, pp. 31-37

9 Así se puede apreciar en los trabajos de PESET, J.L. (1987), Ciencia y libertad. El papel del científico ante la independencia americana, Madrid; SILVA, R. (1988), Prensa y Revolución a finales del siglo XVIII. Contribución a un análisis de la formación de la ideología de independencia nacional, Bogotá; SALADINO, A. (1990), Dos científicos de la Ilustración hispanoamericana: J.A. Alzate y F.J. de Caldas, México y GLICK, Thomas F. (1991), "Science and Independence in Latin America (with Special Reference to New Granada)" The Hispanic American Historical Review, vol. 71, n 2, pp. 307-334

10 Sobre esta empresa cultural ver los trabajos de CLEMENT, J.P. (1979), Indices del Mercurio Peruano 1790-1795, Lima y "L'apparition de la presse periodique en Amérique espagnole: Le cas du Mercurio Peruano", en AA.VV. (1987), L'Amérique espagnole à l'époque des lumières. Tradition, Innovation, Représentations, Paris, pp. 273-286 
el dios que transporta los mensajes y establece la aproximación, las conexiones, entre emisores y receptores de esos mensajes. En efecto, esos periódicos científicos que surgieron en los diversos centros virreinales a fines de la época colonial fueron mensajeros de la ciencia: importaron y exportaron conocimientos atravesando con su quehacer la parte de la sociedad sobre la que se irradió su influencia.

Ese trasvase de conocimientos generó un optimismo histórico entre las élites locales de los virreinatos americanos, como sucedió en el de la Nueva Granada. En este territorio emergió la figura de Francisco José de Caldas, uno de los más importantes mensajeros de la ciencia ilustrada hispano-americana, quien el 5 de abril de 1801 escribe desde Popayán a Bogotá a Santiago Arroyo para transmitirle la siguiente predicción:

\footnotetext{
"Se acercan, mi amigo, los días de ilustración y gloria para Nueva Granada. ¿Veremos nosotros esta feliz revolución? $\mathrm{Si}$..no se oprimen los talentos con ideas y juramentos dignos de los siglos de los Godos, estoy seguro que al expirar el siglo XIX no tendremos que envidiar a la Metrópoli su ilustración y sus talentos literarios"'l.
}

Caldas fue seducido a fines del siglo XVIII por las ideas ilustradas sobre la utilidad de la nueva ciencia para el progreso del Estado y la felicidad pública que Mutis y el círculo de sus discípulos difundieran en las páginas del Papel periódico de Santa Fé de Bogotá publicado entre 1791 y 1797. Decidió entonces abandonar poco a poco los negocios mercantiles que su familia de Popayán practicaba en la importante vía comercial que iba de Quito a Cartagena de Indias, y dedicarse con esmero y pasión a practicar la nueva ciencia como astrónomo, físico y botánico ${ }^{12}$.

En el ejercicio de esa práctica científica concedió una gran importancia a la formación y despliegue de redes de comunicación científica con sus pares y con la incipiente ciudadanía neogranadina. Ese afán se manifestó en la labor divulgativa de conocimientos científicos que promovió y llevó a cabo, impulsado por su creencia de que el uso de la ciencia podía ser una fuerza cohesionadora de los diferentes territorios que formaban el virreinato de Nueva Granada, poblado en aquel entonces por unos dos millones de habitantes ${ }^{13}$.

Así el 6 de mayo de 1802, desde Quito, manifestó a uno de sus amigos de Popayán su intención de convertirse en " el canal de comunicación", de las ideas ilustradas entre los jóvenes neogranadinos, aduciendo que así no habría que mendigar a

11 CALDAS, F.J. [1801] (1917), Cartas. Recopiladas y publicadas por Eduardo Posada, Bogotá, p. 43

12 Un estudio, entre otros muchos, del itinerario intelectual y científico de Caldas se encuentra en el estudio introductorio de CHENU, J. (1992), a Francisco José de Caldas. Un Peregrino de las ciencias, Madrid, 1992, pp. 7-61

13 Sobre esta cuestión ver CHENU, J. (1987), "De la terre aux etoiles: Quête scientifique et identité culturelle en Nouvelle Grenade", en AA.VV (1987), pp. 247-260 
Humboldt, quien recorría por aquel entonces el virreinato neogranadino, dado que "no somos menos inventores que los europeos".

Esa oferta logró concretarla seis años después. Fue entonces cuando Caldas lanzó el Semanario de Nueva Granada, ya desde una posición científica consolidada como miembro de la real expedición botánica de Santa Fe de Bogotá, catedrático de matemáticas del Colegio Real Mayor de Nuestra Señora del Rosario y encargado del Observatorio Astronómico de Bogotá, que Mutis había creado a principios de esa década con apoyo virreinal.

El Semanario, que se edita entre 1808-1810, teje una red de comunicación en todo el virreinato desde Caracas a Loja, desde Panamá a Cuenca. Pero sus dos centenares largos de suscriptores estaban concentrados fundamentalmente en las ciudades de Bogotá, que por aquel entonces tenía unos 22.000 habitantes, Popayán, y sobre todo Cartagena, donde el consulado de comercio, presidido por Josef Ignacio de Pombo, uno de los mecenas de Caldas, realizó una activa campaña proselitista entre hacendados y mercaderes obteniendo unas 50 suscripciones. Caldas lo agradece enfáticamente: "su amor a la ilustración pública, y su patriotismo..debe servir de modelo a los demas Cuerpos del Reyno, y.. al mismo tiempo llena de reconocimiento al Editor del Semanario".

Esa publicación permitió, por tanto, establecer una sólida alianza entre los medios científicos del Observatorio de Santa Fe y los comerciantes ilustrados de Cartagena, porque ambos participaban de un mismo programa de valores y virtudes que se expresaba en el uso de un lenguaje compartido.

Caldas, los colaboradores del Semanario y sus suscriptores comparten la convicción de habitar en un espacio singular, desde el que era posible llegar al conocimiento de lo universal a partir del estudio de las condiciones locales: ".. el habitante de las regiones equinocciales conoce todas las formas vegetales que la naturaleza ha colocado en su país favorecido, y la tierra ostenta a sus ojos un espectáculo tan variado como el que le presenta la bóveda azul del cielo, en la cual no hay constelación que se le oculte" expresa Caldas al presentar a los lectores del Semanario el Prospecto de la Geografía de las Plantas de Humboldt, editado en Europa.

El Semanario pretendió, pues, como expuso Caldas, ofrecer "artículos interesantes, curiosos, útiles y dignos de la atención del Público ilustrado". Pero ese público no fue tan numeroso como Caldas preveía y a veces se mostró renuente a comprender la función didáctica del periódico y la convicción de su editor de que sus trabajos astronómicos contribuían a mejorar la geografía, los caminos y el comercio del virreinato. El duro contacto con la realidad hizo que el optimismo de Caldas de una década antes se atemperase, y que constatase hacia 1809 que "es cosa bien triste que la capital del Nuevo Reino de Granada no pueda sostener dos o tres años un papel público".

Pero dos hechos contribuyeron a mitigar su decepción: en primer lugar su consideración de que "apenas tenemos 300 años de existencia, y no se nos pueden exigir 
las luces y los conocimientos de Europa"14, y en segundo lugar el hecho de que las páginas del Semanario fueran apreciadas por algunos de sus colegas, distantes de Bogotá, como el caraqueño Andrés Bello, - editor en ese momento del periódico $E l$ Lucero patrocinado por el Consulado de esa ciudad venezolana-, y un grupo cualificado de científicos y técnicos peruanos, la mayor parte de ellos antiguos mercuristas: el protomédico del Perú Hipólito Unanue, los profesores de Física y Matemáticas del Real Colegio de San Fernando de Lima Josef Coquette y Gregorio Paredes, el economista Pedro Abadia, segundo factor de la Real Compañía de Filipinas en Lima, y Tadeo Haenke, el naturalista bohemio que había participado en el viaje alrededor del mundo de Malaspina, y que, residente en la actual ciudad boliviana de Cochabamba, cultivaba allí la Botánica y la Meteorología, y era un activo corresponsal de los periódicos ilustrados de Buenos Aires, como el Telégrafo Mercantil de Cabello, el Semanario de Agricultura de Vieytes y Cerviño o el Correo de Comercio de Manuel Belgrano.

Esos mensajeros de la ciencia ilustrada se buscaron y se encontraron y, gracias a las gestiones de Unanue, se estableció una correspondencia meteorológica entre el Observatorio de Santafé, Lima y Cochabamba ${ }^{15}$.

Ahora bien, todo ese proceso acumulativo de conocimientos y todo ese esfuerzo divulgador alentado por los científicos ilustrados sufrió un serio revés en el período 1810-1825, cuando la mayor parte de las colonias españolas americanas lograron su emancipación política de la metrópoli en medio de convulsiones sociales y acciones bélicas. Uno de los símbolos de ese drama fue precisamente el fusilamiento en 1816 de Caldas por los generales del ejército español reconquistador de Morillo, quien no perdonó la participación activa de ese científico en las filas del ejército patriota neogranadino como coronel de Ingenieros.

A pesar de las dificultades socio-económicas y políticas del período postindependista, bastante oscuro historiográficamente, se detecta en las primeras décadas del siglo XIX en toda la América latina la presencia de un periodismo de divulgación científica impulsado por los discípulos de los sabios locales ilustrados, o por científicos y técnicos foráneos, llegados de Europa en su mayor parte, que ofrecieron sus servicios a los nuevos Estados independientes. Ese periodismo tuvo un carácter intermitente y discontinuo, siendo escasa la duración de gran parte de esas publicaciones. Pero ese inconveniente no impidió que la voluntad divulgadora de esos publicistas de la ciencia fuese permanente, como atestigua la trayectoria de muchos de esos científicos y técnicos, como el peruano Mariano Eduardo de Rivero. Este químico y mineralogista fue contratado en Europa en 1822 por Zea y Bolívar para poner en marcha en Bogotá, junto a Boussingault y otros científicos franceses, una escuela destinada a la

\footnotetext{
14 Ver Semanario de Nueva Granada, Bogotá, reed. 1942, tomo III, p. 18

15 Ver Memoria $7^{a}$. Continuación del Semanario del Nuevo Reino de Granada. Que contiene los preliminares al Almanaque del Nuevo Reino de Granada para 1811, pp. 30-32
} 


\section{LEONCIO LÓPEZ-OCÓN CABRERA}

formación de ingenieros civiles y militares. Tras fracasar en la organización de esa empresa colombiana, se esforzó en su país natal, a través de una amplia labor publicitaria, en promover los conocimientos mineralógicos que había adquirido en Freiberg y en París, y la afición a la arqueología, al estudio de los monumentos de los antiguos peruanos que eran "testigos elocuentes de su saber, grandeza y vicisitudes"16.

La voluntad de esos científicos y técnicos de comunicar sus diversos conocimientos a un público formado por hacendados, mineros y comerciantes de las clases altas latinoamericanas, y por profesionales de las incipientes clases medias, estaba estimulada por una doble motivación político-ideológica. Una palanca de su acción divulgadora estaba formada por una visión democrática del saber ${ }^{17}$, compartida por muchos círculos científicos y políticos de todo el espacio afectado por el ciclo de las revoluciones atlánticas. Así el mexicano Andrés Quintana Roo, que se había destacado en el periodismo insurgente, justificó de esta manera la creación en 1826 del Instituto de Ciencias, Literatura y Artes de México: "no basta, para la utilidad de las ciencias, que un corto número de hombres las posea con perfección: es preciso que su luz, difundiéndose en el común del pueblo, sea, por decirlo así, tan democrática como el gobierno"18. El segundo aliento de esa acción cultural venía dado por la convicción de muchos de esos divulgadores de que el cultivo de las ciencias, fundamentalmente las naturales, era un instrumento fundamental para construir las nuevas naciones al fomentar el amor a la tierra propia, y al favorecer el conocimiento y aprovechamiento de los recursos naturales nativos, fuente del bienestar material de sociedades cuyas riquezas procedían de la exportación de sus productos agrícolas y mineros.

Esa labor divulgativa, llevada a cabo en un escenario lleno de dificultades por una pléyade de científicos, fundamentalmente naturalistas, favoreció el asentamiento de una cultura científica en la nueva América latina independiente a través de una triple vía.

16 Rivero editó en Lima en 1828, junto a su amigo Nicolás Piérola, la revista titulada Memorial de Ciencias Naturales y de Industria destinada fundamentalmente a la instrucción de los mineros peruanos. Una antología de sus escritos científicos, publicados varios de ellos en la prensa periódica peruana, fue editada con el título Colección de memorias científicas, agrícolas e industriales, publicadas en distintas épocas por Mario de Rivero y Ustáriz (Bruselas, 1857, 2 vols.). Mariano Eduardo de Rivero y Ustáriz es autor asimismo junto al naturalista austríaco Juan Diego de Tschudi de la obra Antigüedades peruanas (Viena, 1851), 2 vols. in fol., uno de ellos de láminas. La cita corresponde a Colección de memorias..., vol.I, p. V

17 Sobre esta cuestión ver SALDAÑA, J.J. (1996) "Ciencia y libertad: la ciencia y la tecnología como política de los nuevos estados americanos”, en SALDAÑA, J.J. ed., (1996), Historia social de las ciencias en América Latina, México, pp. 283-298

18 Andrés Quintana Roo, "Discurso inaugural que en la solemne instalación del Instituto mexicano de ciencias, literatura y artes pronunció su vicepresidente el Sr. D...", en Memorias del Instituto de Ciencias, Literatura y Artes, t.I, (México, 1826), pp. 24-25. Citado por RODRIGUEZ, L. (1992), "Ciencia y Estado en México: 1824-1829", en SALDAÑA, J.J. (ed.) (1992), Los orígenes de la ciencia nacional, México, p. 166 


\section{LA FORMACIÓN DE UN ESPACIO PÚBLICO PARA LA CIENCIA EN LA AMÉRICA LATINA DEL S. XIX}

En primer lugar logró preservar los esfuerzos científicos ilustrados mediante el cultivo de una memoria científica y la reelaboración de una tradición. A lo largo del segundo tercio del siglo XIX se hicieron reediciones de algunos de los más importantes periódicos del período ilustrado ${ }^{19}$, y surgieron diversas sociedades científicas, particularmente en México, Brasil y Colombia ${ }^{20}$, cuyos objetivos principales eran el propagar los conocimientos científicos y el proseguir los programas de investigación emprendidos a fines de la época colonial. Así, la sociedad de Naturalistas Neogranadinos, fundada en 1859, pretendía sistematizar los conocimientos indígenas sobre la flora neogranadina y reanudar las investigaciones sobre plantas útiles efectuadas por la expedición botánica de Mutis y por Humboldt y Bonpland ${ }^{21}$.

En segundo lugar esa actividad divulgativa influyó tanto en el ámbito político como en el cultural.

Muchos gobernantes latinoamericanos, fuesen liberales o conservadores, mostraron a lo largo del segundo tercio del siglo XIX, si bien con desiguales resultados, empeño por fomentar las actividades científico-técnicas. Si en el caso de México parece ser que la promoción de la aplicación técnica de los conocimientos científicos tuvo un relativo éxito a partir de la creación en 1853 del Ministerio de Fomento, Colonización, Industria y Comercio ${ }^{22}$, en el caso colombiano, sin embargo, el decidido esfuerzo de poner en marcha una educación técnica en los años 1840 y 1850 tuvo menores resultados ${ }^{23}$.

19 Así a principios de la década de 1830 se efectuó una reedición de la obra periodística del naturalista mexicano Alzate. Ver Gacetas de literatura de México, por D. José Antonio Alzate Ramírez, Puebla, reimpresa en la oficina del hospital de S. Pedro, a cargo del ciudadano M. Buen Abad, 1831, 4 vol. A su vez, a fines de la década de 1840 el colombiano Joaquín Acosta publicó en Paris una antología de la obra de divulgación científica de Caldas. Ver Semanario de la Nueva Granada, miscelánea de ciencias, literatura, artes e industria, publicada bajo la dirección de Francisco José de Caldas. Nueva edición aumentada con varios opúsculos inéditos de F.J. de Caldas..adornada..con el cuadro original de la geografía de las plantas del Barón de Humboldt, Paris, 1849

20 Sobre esta cuestión ver el número monográfico coordinado por VESSURI, H. y CAPEL, H. (1992) en la revista Interciencia (Caracas), vol. $17, \mathrm{n}^{\circ} 3$, dedicado al estudio de las asociaciones científicas del siglo XIX en la América latina, en el que se recogían los trabajos presentados en un simposium del congreso internacional "Ciencia, descubrimiento y mundo colonial", celebrado en Madrid entre el 25 y el 28 de junio de 1991. Sus actas fueron editadas por LAFUENTE, A., ElENA, A., y ORTEGA, M.L. (1993), Mundialización de la ciencia y cultura nacional, Madrid.

21 Sobre esta cuestión ver por ejemplo el texto del naturalista amateur, el abogado Florentino Vezga, "Memoria sobre la historia del estudio de la botánica en la Nueva Granada", en el primer número del Boletín de la Sociedad de Naturalistas Neogranadinos, comentado en OBREGóN, D. (1992), Sociedades científicas en Colombia. La invención de una tradición 1859-1936, Bogotá, pp. 13-20

22 Ver TRABULSE, E. (1991), "Ciencia y Tecnología en México a mediados del siglo XIX", en Crítica y heterodoxia. Ensayos de historia mexicana, 1991, pp. 121-128

$23 \mathrm{Al}$ respecto ver SAFFORD, F. (1976), The Ideal of the Practical, Colombia's Struggle to Form a Technical Elite, Austin \& London. 
Y en la esfera cultural cabe apreciar cómo diversos literatos, incitados por una estética romántica que admiraba las fuerzas vitales de la naturaleza y los espectáculos telúricos, encontraron motivos de inspiración en el carácter sublime de las bellezas naturales de su geografía y en la especificidad y originalidad de sus creaciones culturales. A su vez esas manifestaciones literarias, por un efecto de retroalimentación, contribuyeron a impulsar la observación, el estudio y la comprensión de la naturaleza y de las sociedades americanas. Así, parte de la obra poética del venezolano-chileno Andrés Bello (1781-1865), —sobre todo su traducción al español de una parte del poema "Des Jardins" de Jacques Delille, y su famosa "Silva a la agricultura de la zona tórrida"24_, puede ser leída como una manifestación de las influencias que en la opinión pública estaban generando los estudios que los naturalistas pre-románticos y románticos estaban realizando sobre la vegetación de la América tropical. Es esclarecedor al respecto que mientras Bello redactaba en Londres en la década de 1820 su "Silva a la agricultura de la zona tórrida", donde canta la fecundidad de la naturaleza de la América tropical y enumera sus principales producciones agrícolas, simultáneamente elabora textos de divulgación sobre esa misma naturaleza, que se publicaban en las revistas londinenses editadas por diversos liberales latinoamericanos, y españoles exiliados ${ }^{25}$. Y es significativo que entre esos trabajos ocupen un lugar preponderante sus comentarios y críticas al "Viaje a las regiones equinocciales del Nuevo Continente por Alejandro de Humboldt y Amado Bonpland", en el que se presentaban al público del Viejo y el Nuevo Mundo de manera sintética y panorámica todas las maravillas de la naturaleza y los logros civilizatorios de la América intertropical.

Y en tercer lugar cabe señalar que la irradiación de las influencias de esa labor divulgadora, perceptible sobre todo a partir de mediados de siglo, generó en ciertos miembros de las élites científico-técnicas latinoamericanas autoconfianza en sus fuerzas, y un afán de compromenterse en la vida cultural de los países en los que desplegaban sus actividades. Estos sentimientos se observan, por ejemplo, en la efímera Revista de Ciencias y Letras de Santiago de Chile, cuyo consejo de redacción ${ }^{26}$ estaba formado

\footnotetext{
24 Estos poemas se publicaron por primera vez en la revista editada en Londres El Repertorio Americano, respectivamente en el vol. IV, agosto de 1827, pp. 1-10 y en el vol.I, octubre 1826, pp. 7-18. Están más accesibles en BELLO, A., (1981), Obras Completas, vol. I. Poesías, pp. 103-126 y 65-74

25 Esos trabajos londinénses de divulgación científica de Bello sobre la naturaleza americana aparecieron publicados en El Censor Americano (1820), La Biblioteca Americana (1823), El Repertorio Americano (1826 y 1827). Han sido reproducidos en BELLO, A. (1981), Obras completas. vol. XXIV. Cosmografia y otros escritos de divulgación científica, Caracas, pp. 271-491

26 Ese consejo de redacción estaba formado entre otros por: el rector Andrés Bello, el francés Courcelle-Seneuil, profesor de economía política, el lituano-polaco Ignacio Domeyko, que por aquel entonces era el secretario de la Facultad de Ciencias Físicas y Matemáticas y profesor de química y mineralogía, el alemán Rudolfo Philippi, profesor de botánica y zoología, exiliado a Chile tras el fracaso en Europa de la revolución democrática de 1848, y el decano de la Facultad de Medicina, el francés Lorenzo Sazie.
} 
por diversos integrantes de la prestigiosa Universidad de $\mathrm{Chile}^{27}$, de la que era rector el ya mencionado Andrés Bello. Según el autor del prospecto de presentación de esa publicación su edición tenía el doble objetivo de alentar el adelantamiento de las letras y las ciencias en Chile y poner "al alcance de los otros pueblos civilizados lo que por nuestras investigaciones podamos agregar a lo que actualmente posee i disfruta el mundo literario, i sobre todo el científico, que necesita de nuestra cooperación i la reclama con insistencia" 28 .

Esta serie de fenómenos favorables a la creación de un público para la ciencia, que pueden ser rastreados durante la época romántica, entre 1825 y 1860 , en diversas partes de la América latina, como México, Brasil, Chile, Colombia, Perú o Argentina, se generalizaron y amplificaron durante el medio siglo posterior por toda esa área cultural. En esa etapa crecieron cuantitativa y cualitativamente los instrumentos destinados a propagar los conocimientos científico-técnicos y a favorecer la comunicación entre los sabios y aficionados al cultivo de las ciencias. En efecto, entre 1860 y 1910, grosso modo, proliferaron en los diversos países de la América latina instituciones, sociedades y periódicos que contribuyeron a consolidar la creación de un espacio público para la ciencia en ese área periférica de la ciencia-mundo.

Diversos factores culturales, económicos y socio-políticos contribuyeron a que durante ese período se desarrollase una etapa de esplendor en la popularización de los conocimientos científico-técnicos.

El positivismo, en efecto, irrumpió con extraordinaria fuerza en el escenario cultural latinoamericano. Durante el último tercio del siglo XIX se convirtió en diversos países en la ideología oficial de las élites políticas y culturales liberales, a las que ofreció un conjunto de medidas para reformar la educación y favorecer la inserción cultural de la ciencia. Su influencia es notoria no solo allí donde tuvo una gran presencia, como fue el caso del Brasil y México, sino que cabe hallarla esparcida por todas partes: desde Argentina a Venezuela, desde Chile a Ecuador ${ }^{29}$. En todos los

27 Acerca de la significación e importancia de esa institución en el desenvolvimiento de la cultura cientifica chilena ver JAKSIC, I. y SERRANO, S. (1990), "In the Service of the nation: the establishment and consolidation of the Universidad de Chile, 1842-79", The Hispanic American Historical Review, vol. 70, $\mathrm{n}^{\circ}$ 1, pp. 139-171 y SERrANO, S. (1994), Universidad y nación. Chile en el siglo 19, Santiago de Chile.

28 Revista de Ciencias y Letras, tomo I, $\mathrm{n}^{\circ} 1$, Santiago, abril de 1857, prospecto pp. 5-8, especialmente p. 6.

29 De la abundante bibliografía existente sobre el positivismo en la América latina cabe destacar: ZEA, L. (1968), El Positivismo en México: nacimiento, apogeo y decadencia, México y (1980), Pensamiento positivista latinoamericano, Caracas, 2 vols.; TERAN, O. (1987), Positivismo y nación en la Argentina, Buenos Aires; CRUZ COSTA, J. (1958), O positivismo na República: notas sobre a historia da positivismo no Brasil, Sao Paulo y LINS, I. (1964), Historia do positivismo no Brasil, Sao Paulo. 


\section{LEONCIO LÓPEZ-OCÓN CABRERA}

lugares los positivistas emprenden una "cruzada cientificista" 30 . Crean instituciones educativas, como la Escuela Preparatoria de México, dirigida durante más de una década —entre fines de 1867 y principios de 1878 - por el discípulo de Augusto Comte, el médico Gabino Barreda ${ }^{31}$. Esparcen sus ideas por periódicos y revistas, como El Método y El Positivismo, fundadas en México en la década de 1880 por Porfirio Parra, el principal discípulo de Barreda. Se ganan la adhesión a su causa de los políticos, como los que dirigen la República liberal mexicana desde 1867, o los que crean la Primera República en el Brasil a partir de 1889. Fomentan el espíritu de asociación para difundir sus ideales.

Esas sociedades científicas, alentadas por el espíritu positivista, se dedicaron a propagar, mediante la escritura y la palabra, conocimientos científicos y técnicos de contenido utilitarista, que en su opinión favorecerían el avance del saber y el incremento del bienestar humano. Por ejemplo, en el primer número de la revista $\mathrm{La} \mathrm{Na-}$ turaleza, en 1869, José J. Arriaga, socio de número de la Sociedad Mexicana de Historia Natural, presentó un trabajo sobre "El microscopio y la fotografía aplicados al estudio de las ciencias naturales", o se difundieron una serie de recetas para teñir la seda, la lana y el algodón con los colores de la anilina.

Los integrantes de esas sociedades mostraron además preocupación por cultivar el rescate de sus respectivas tradiciones científicas y salvaguardar su patrimonio cultural. Así, durante sus primeras décadas de existencia, la Sociedad Geográfica de Lima cuidó el archivo de Raimondi, el naturalista de origen italiano que entre 1850 y 1880 sentó las bases de la geografía contemporánea del Perú, y en cuya obra $E l P e$ $r u ́$, editada lujosamente por el gobierno civilista de Manuel Pardo en la década de 1870, realizó una recuperación de los estudios geográficos que se habían efectuado en ese territorio andino durante la época colonial y primeras décadas del siglo XIX ${ }^{32}$.

La existencia de esas sociedades científicas dio nueva vida o favoreció la creación de Museos de historia natural y arqueológicos.

En 1877, por ejemplo, el Museo Nacional de México inició una nueva etapa en su ya larga andadura, pues su fundación se remontaba a 1822, y empezó a editar unos cuidados Anales bajo la dirección del arqueólogo e historiador Gumersindo Mendoza, con el patrocinio del ministro de Justicia e Instrucción Pública Ignacio Ramírez,

30 Una reciente visión panorámica sobre los logros y limitaciones de la acción "cientificista" de los positivistas la ofrece WEINBERG, G. (1996), "La ciencia y la idea de progreso en América Latina, 18601930", en SALDAÑA, J.J. ed. (1996), pp. 349-436.

31 Sobre las relaciones de Barreda con Augusto Comte y el positivismo francés ver GoNZALEZ NAVARro, M. (1959), "Los positivistas mexicanos en Francia", Historia Mexicana, IX, 1, pp. 119-129 y ARAGON, A. (1898), "A la memoria del doctor Gabino Barreda", reeditado en ZEA, L. ed., (1980), vol. I. pp. 199-231.

32 Un análisis más detallado del proyecto cultural de los integrantes de esa sociedad científica en LOPEZ-OCON, L. (1995), "El nacionalismo y los orígenes de la Sociedad Geográfica de Lima", en CUETO, M. (1995), ed. Saberes andinos. Ciencia y tecnología en Bolivia, Ecuador y Perú, Lima, pp. 109-125. 
una de las cualificadas figuras del liberalismo mexicano. Influido por el ideario positivista, Mendoza, en el prólogo del primer número de esa publicación, enfatizó su afán de poner la ciencia al alcance de todos, dado que el gobierno estaba de acuerdo en que la función del Museo era "vulgarizar los conocimientos científicos y difundirlos entre todas las clases de nuestra sociedad". El objetivo de esa publicación era doble: contribuir, por una parte, al conocimiento de las costumbres de los animales, los usos de las plantas, y la ventaja de las aplicaciones de la Geología y la Paleontología para el aprovechamiento de los minerales y fósiles de las vastas regiones de la república mexicana; y, por otra, a la popularización de la Arqueología, mejorando el conocimiento del remoto pasado de México con el fin de "formarse una idea clara acerca del origen de nuestros padres, de sus ideas religiosas y políticas, de sus usos y costumbres, tales como están representadas todas estas cosas en los restos de sus monumentos, en sus dioses y geroglíficos que han podido escapar de la acción del tiempo y de los hombres". Para realizar esa labor Mendoza logró contar con la inestimable colaboración de los arqueólogos Orozco y Berra y Chavero ${ }^{33}$.

En Argentina, por su parte, se fundó en la ciudad de La Plata en 1884 un impresionante Museo General, que fue abierto al público en 1887, con el fin de emular a la Smithsonian Institution en la nueva Washington austral. La construcción del gran edificio neoclásico fue apoyada con entusiasmo por el gobernador provincial Carlos D'Amico, y supervisada por el cerebro de toda la operación, el naturalista Francisco Moreno, quien, como manifestaría a un colega norteamericano, entregó al Museo de La Plata su vida, sus fuerzas, sus colecciones paleontológicas, su dinero. Afirmación - esta última que no ha de extrañar porque a principios de la década de 1890 editó con su peculio unos lujosísimos Anales del Museo. El éxito de público fue en todo caso rotundo, al menos en los primeros años de funcionamiento del Museo. Los cerca de 50.000 visitantes que tuvo en 1888 podían contemplar, a través de sus magníficas colecciones, la historia de la tierra y de la vida en la tierra según planteamientos evolucionistas ${ }^{34}$.

El programa de aculturación científica desplegado por los positivistas se vio además favorecido por las nuevas oportunidades económicas que tuvo la región en el último tercio del siglo XIX. En ese período de tiempo ciertas áreas de la región latinoamericana se insertaron de manera decidida en el mercado mundial gracias a la

33 Para más detalles sobre el desarrollo del Museo Mexicano ver FlORESCANO, E. (1993), "La creación del Museo Nacional de Antropología y sus fines científicos, educativos y políticos", en FLORESCANO, E. (1993), comp. El patrimonio cultural de México, México, pp. 150-158.

34 Ver SHEETS-PYENSON, S. (1988), Cathedrals of Science. The Development of Colonial Natural History Museums during the Late Nineteenth Century, Kingston \& Montreal, p. 66. Sobre el proyecto nacionalista de Moreno subyacente a sus actividades científicas ver QUIJADA, M. (1998), "Ancestros, ciudadanos, piezas de museo. Francisco P. Moreno y la articulación del indígena en la construcción nacional argentina (siglo XIX)", Estudios interdisciplinarios de América Latina y el Caribe, Tel Aviv, vol. $\mathrm{X}, \mathrm{n}^{\circ} 2$, (en prensa). 


\section{LEONCIO LÓPEZ-OCÓN CABRERA}

puesta en valor de una serie de materias primas y recursos naturales reclamados por los consumidores europeos. Las economías latinoamericanas experimentaron entonces un notable crecimiento, que permitió incrementar sustancialmente los recursos fiscales. Y esta mejora de ingresos permitió reorganizar el sistema educativo, crear instituciones científicas (como observatorios astronómicos, gabinetes de física, museos de historia natural, institutos biológicos o comisiones geológicas), acometer la creación de grandes obras de infraestructura, como ferrocarriles y puertos, o desarrollar la navegación a vapor en las grandes cuencas fluviales sudamericanas.

Una de las repercusiones de ese crecimiento económico fue el interés mostrado por la prensa de divulgación científico-técnica en las cuestiones tecnológicas. El afán de fomentar mejoras materiales mediante una política desarrollista alentó, en efecto, a las élites técnicas a llevar a cabo campañas para combatir el atraso industrial de sus países, y potenciar su educación técnica. Ingenieros - que se autoconcibieron como administradores de la tecnología - y agrónomos, que querían trasplantar y adecuar a la América latina los logros de la agricultura científica europea basada en los avances de la química, discutieron ampliamente en las páginas de los periódicos latinoamericanos sobre las nuevas tecnologías que habían de aplicarse para la mejora de las redes de transporte, y la transformación de sus productos agropecuarios.

Esa sensibilidad tecnológica se aprecia, por ejemplo, en periódicos chilenos, como El Ferrocarril de Santiago o el Boletín de la Sociedad Nacional de Agricultura ${ }^{35}$, o en publicaciones peruanas, como la Revista de Agricultura (1875-1876) de Lima ${ }^{36}$; es visible en los grandes periódicos y revistas de la ciudad de Bogotá del último cuarto de siglo, como el Repertorio Colombiano (1878-1899), el Papel periódico ilustrado (1881-1888) y Colombia ilustrada (1889-1892) ${ }^{37}$, o en otras publicaciones colombianas especializadas en agricultura, como El Agricultor (1873-1901) o La Gaceta Agrícola de Cartagena (1879-1892), —que en sus dos primeros años logró una cir-

35 Ver por ejemplo los artículos del consultor técnico del gobierno chileno el ingeniero francés Eduardo Salles, "Los ferrocarriles y el cuerpo de ingenieros civiles de Chile" en El Ferrocarril, Santiago de Chile, 24 de octubre de 1861 o de Félix Echeverría, "Las máquinas y el trabajador agrícola", en Bole tín de la Sociedad Nacional de Agricultura, Santiago, vol, II, $\mathrm{n}^{\circ} 21,1871$, pp. 376-378, citados y comentados en GUAJARDO SOTO, G. (1990), "Las opciones tecnológicas de la oligarquía chilena en el siglo XIX (1852-1884)", Quipu, vol. 7, n 2, pp. 187-216.

36 Esta publicación fue fundada y dirigida por el agrónomo francés J.B.H. Martinet. Era una publicación mensual redactada casi exclusivamente por el mismo Martinet. En la sección de anuncios de su número 7 , correspondiente a enero de 1876, aparecía publicidad de las máquinas agrícolas e industriales de la empresa L. Kuffre y Cía de Lima con un grabado de una máquina de vapor, así como del establecimiento de horticultura de Guillermo Klug dedicado al cultivo de árboles de alameda y plantas exóticas de todas las clases, y del laboratorio industrial y comercial para el análisis químico del azúcar que tenía el mismo director-redactor de la publicación $\mathrm{H}$. Martinet.

37 Existen índices de estas publicaciones realizados por J. ORTEGA TORRES, editados en 1961 por el Instituto Caro y Cuervo de Bogotá. 
culación de nueve mil ejemplares-38, o en ingeniería como los influyentes Anales de Ingeniería (1887-1935); y se detecta asimismo en numerosos periódicos mexicanos $^{39}$, en textos de periódicos brasileños, como el Journal de Comercio y la Gazeta de Noticias de la década de $1880^{40}$ y en publicaciones argentinas ${ }^{41}$.

Así pues, la labor proselitista emprendida por los positivistas latinoamericanos, concebida como una misión sacerdotal análoga a la de sus homólogos europeos ${ }^{42}$, no sólo contribuyó a favorecer una interrelación entre actividades de investigación y de divulgación científica, sino también a dotar de mayor autoconfianza a las élites científico-técnicas latinoamericanas que fueron capaces de hacer compartir su sueño de llevar orden y progreso a través del cultivo de las ciencias a otras capas sociales urbanizadas y alfabetizadas, que, aunque muy minoritarias en el conjunto de la población latinoamericana, mayoritariamente rural y analfabeta, mostraron gran confianza en el poder redentor de la ciencia al imbuirse de una mentalidad cientificista. Este credo fue expresado con elocuencia por el literato peruano González Prada, quien haría esta profesión de fe: "la ciencia positiva, que en un siglo de aplicaciones industriales ha producido más bienes a la humanidad que en milenios de teología y metafísica, (es) ese redentor que nos enseña a suavizar la tiranía de la naturaleza"43.

\section{LA PROYECCIÓN EXTERIOR DE UN FENÓMENO}

Todo ese proceso de creación de un espacio público para la ciencia, basado en una serie de instrumentos y numerosos actores con variadas motivaciones, cuyo mo-

\footnotetext{
38 BEjARANO, J. A. (1993), "Notas para una historia de las ciencias agropecuarias en Colombia", en RESTREPO, O. et al. (1993), Historia natural y ciencias agropecuarias, tomo III de la Historia social de la ciencia en Colombia, Bogotá, p. 396.

39 Dos trabajos panorámicos sobre el periodismo mexicano del siglo XIX referente a cuestiones tecnológicas son los de BARBERENA BLASQUEZ, E. y BOLCK ITURRIAGA, C. (1986), "Publicaciones periódicas científicas y tecnológicas mexicanas del siglo XIX: un proyecto de base de datos", Quipu, vol. 3, n 1, pp. 7-26 y MORENO DE LOS ARCOS, R. y RUIZ DE ESPARZA, J. (1972), "Apuntes sobre el periodismo tecnológico mexicano en los siglos XVIII y XIX", Anales de la Sociedad Mexicana de Historia de la Ciencia y la Tecnología, $\mathrm{n}^{\circ} 3$, pp. 341-352.

40 PITA Freitas Filho, A. (1992), "A tecnología agrícola e exposiçao nacional de 1881", Quipu, vol. $9, \mathrm{n}^{\circ} 1$, pp. $75-88$.

41 LERTORA MENDOZA, C. (1997), "La ciencia nacional en las revistas de difusión científica argentina: 1880-1920", en ARBOLEDA, L.C. y OSORIO, C., Nacionalismo e Internacionalismo en historia de las ciencias y la tecnología en América latina, Cali, pp. 375-389.

42 Sobre esta cuestión ver PETIT, A. (1989), "La diffusion des sciences comme devoir positiviste", en Romantisme, $\mathrm{n}^{\circ}$ 65, pp. 7-25 y BENSAUDE-VINCENT, B. (1987), "Auguste Comte, la science populaire d'un philosophe", Corpus, ${ }^{\circ}$ 4, pp. 143-166.

43 Gonzalez Prada, M. (1976), Páginas libres. Horas de lucha, Caracas, citado por ZEA, L. (1980), Pensamiento positivista latinoamericano, Caracas, vol.I, p. XLII.
} 


\section{LEONCIO LÓPEZ-OCÓN CABRERA}

vimiento diacrónico se ha intentado esbozar, tuvo además una dimensión internacional. Las redes de popularización que hicieron factible la creación de ese espacio público para la ciencia a lo largo de la América latina durante el siglo XIX, no sólo se desplazaron verticalmente en el interior de las respectivas sociedades latinoamericanas, sino que también tuvieron una circulación horizontal, poniendo en contacto a productores y consumidores de la ciencia latinoamericanos con los de otras regiones y áreas del planeta ${ }^{44}$. En dos de esas redes de popularización de tipo horizontal conviene fijar la atención: en las empresas periodísticas que trasladaron la ciencia europea a la América latina, y viceversa la latinoamericana a Europa, y en la participación latinoamericana en las Exposiciones universales.

En Europa y en Norteamérica surgieron diversas iniciativas a lo largo de la segunda mitad del siglo XIX para participar en ese proceso de creación de un espacio público para la ciencia en la América latina.

Entre esas iniciativas sobresalen una serie de periódicos quincenales, que empezaron a editarse bien en Madrid, - como la Revista Española de Ambos Mundos (1853-1855), La América (1857-1874, 1879-1886), El Museo Universal (18571868), La Ilustración Española y Americana (1869-1921)—o en París como El Eco Hispano-Americano (1853-1871) y Europa y América (1880-1895), que actuaron como redes de comunicación científica trasatlántica.

En el desarrollo de esa labor el caso del periódico El Eco Hispano-Americano debe de ser resaltado al actuar como un singular mecanismo de propagación del ideario positivista en tierras latinoamericanas. En su cabecera aparecía visiblemente el lema positivista "Orden y Progreso", y su director, el español José Segundo Flórez, era un hombre de confianza de Augusto Comte, al que consideraba el "Bacon de nuestra época". Dado el interés de Comte y de sus seguidores por la popularización de la ciencia, se concedió en las páginas de esa publicación importancia a la divulgación de conocimientos científicos y técnicos. En esa tarea destacó entre 1854 y 1858 el naturalista español Ramón de la Sagra, quien, tras haber sido director del Jardín Botánico de La Habana entre 1827 y 1835, finalizaba por esos años su monumental obra sobre Cuba. La Sagra ejerció de portavoz del ideario trasatlántico de ese periódico al informar al público europeo de las riquezas americanas y de los adelantos y progresos científicos, agrícolas e industriales de aquellos países ultramarinos, y, viceversa, al dar cuenta al público latinoamericano del desenvolvimiento científicotécnico europeo. El fue además el responsable durante un lustro de la sección científica, económica e industrial de esa publicación, en donde además de publicar artículos originales suyos sobre diversos temas, se presentaron extractos de los trabajos de

44 Acerca de cómo las sociedades científicas pusieron en funcionamiento redes de popularización de esa índole ver LOPEZ-OCON, L. (1996), "Les sociétés de géographie: un instrument de diffusion scientifique en Amérique latine au début du XX ${ }^{\mathrm{e} m e}$ siècle (1900-1914)", en PETITJEAN, P. ed. (1996), Les sciences coloniales. Figures et institutions, Paris, pp. 79-84. 
las academias y sociedades agrícolas e industriales con las que él estaba en relación, como la Academia de Ciencias o la Sociedad Imperial de Aclimatación de Paris, y en una rúbrica titulada "Hechos y descubrimientos" daba cuenta de las noticias que publicaban "los periódicos tecnológicos y las que nos suministran diariamente nuestras relaciones con hombres especiales, inventores y fabricantes, a la manera de Figuier". Y a partir del número tres, cuando esa sección pasó a denominarse "El precursor de la exposición industrial de 1855", dedicó gran parte de sus energías a dar publicidad de ese evento, y a estimular la participación en él de los latinoamericanos, sin demasiado éxito, pues la presencia latinoamericana en esa exposición de Paris fue reducida ${ }^{45}$.

Pero esas redes de comunicación, que facilitaban la circulación de ideas y conocimientos entre las dos orillas del Atlántico, fueron bidireccionales. Hubo latinoamericanos que se preocuparon por dar a conocer a los europeos la cultura científica que estaba emergiendo en su región. Así sucedió con la Revista Latinoamericana, editada en Paris en 1874, y cuyo director y redactor-jefe fue el cónsul de Colombia en Le Havre Adriano Páez, en la que se presentaron los éxitos obtenidos en certámenes científicos europeos por el botánico colombiano José Jerónimo Triana ${ }^{46}$, se publicaron trabajos de naturalistas y se prestó atención a las contribuciones realizadas por científicos ilustrados y románticos al conocimiento de la naturaleza americana ${ }^{47}$.

Esa orientación bidireccional de las redes de popularización que se expandieron más allá de la región latinoamericana se aprecia sobre todo al hacer el seguimiento de la participación latinoamericana en las exposiciones universales, a las que cabe contemplar como uno de los lugares de iniciación al progreso científico e industrial generados por la "burguesía conquistadora" durante la segunda mitad del siglo XIX, y agentes del doble proceso de mundialización y mundanización que afectó a la expansión de la ciencia occidental en ese período de tiempo, al actuar como lugares de transferencia de ciencia aplicada y concebirse como grandes instrumentos pedagógicos y empresas de formación permanente en una sociedad en constante mutación ${ }^{48}$.

45 Más detalles acerca de esa labor de mediación de El Eco Hispano-Americano en general y de la labor divulgativa en particular de Ramón de la Sagra en LOPEZ-OCON, L. (1996), "Mensajeros de la ciencia en la periferia. La divulgación de los conocimientos científico-técnicos en la América latina durante el siglo XIX a través de la prensa", Región, $\mathrm{n}^{\circ}$ 5, pp. 19-21.

46 Ver Revista Latino-Americana, vol. I, pp. 702-711 y vol. II, pp. 282-306 y 502-507.

47 Entre esos trabajos cabe señalar: "Memoria histórica sobre la vida, carácter, trabajos científicos y literarios y servicios patrióticos de Francisco José de Caldas", por Lino de Pombo (vol.I, pp. 173-191 y 365-385); "Recuerdos de Humboldt en América. Al Dr. Adolfo Ernst por el venezolano Arístides Rojas", (vol. I, pp. 192-210); "Una página de historia. La expedición botánica de Mutis en Colombia" por el colombiano Florentino Vezga (vol. I, pp. 576-582); “Americanos ilustres. Agustín Codazzi”, por el colombiano Manuel Ancízar (vol II, pp. 378-386).

48 He presentado una exposición más detallada de estas cuestiones en "Les expositions universelles comme mécanisme de la mondialisation de la science. La participation de l'Amérique latine dans les 
Ya se ha mencionado que la presencia latinoamericana fue mínima en la Exposición de Paris de 1855, pues a ese certamen solo acudieron 142 expositores de un total de 20.839 , de los que 10.148 eran extranjeros. Pero en las exposiciones siguientes ese número fue creciendo paulatinamente. Y alcanzó un climax en la exposición parisina de 1889 , en la que de un total de 55.000 expositores, más de 5.000 fueron latinoamericanos, los cuales llegaron a obtener más del $10 \%$ de los premios que se concedieron. En efecto, de los 33.639 premios que se otorgaron en esa ocasión los expositores latinoamericanos obtuvieron 3.653, destacando en esa cifra global los 873 premios obtenidos por los mexicanos, los 670 de los argentinos o los 489 de los brasileños ${ }^{49}$.

Para promover y sostener esa presencia latinoamericana en las exposiciones universales del último cuarto de siglo se movilizaron considerables energías y recursos, hasta tal punto que la construcción del pabellón argentino de la Exposición de 1899 costó nada menos que doscientos ochenta mil dólares, cuando el importe total de las importaciones de ese país en ese momento ascendían a 120 millones de dólares. Esa voluntad latinoamericana de estar presentes en esos escenarios en los que se desplegó la cultura científico-técnica de masas de la era del capital se debió fundamentalmente a dos razones: por un afán de aprender en lo que se consideraba que eran grandes escuelas de formación permanente, y por un deseo de mostrar los logros que iba teniendo cada país, y la región en su conjunto, en la senda del progreso, haciendo hincapié en la contribución particular de cada uno de esos países al patrimonio de la humanidad. Es decir, al participar en los flujos de comunicación generados por los espacios expositivos tuvieron un interés particular en crear mecanismos de circulación de ida y vuelta entre Europa y América, y viceversa, de los conocimientos y habilidades que observaban y producían.

Los diferentes comisionados de los gobiernos latinoamericanos tuvieron los ojos abiertos para observar las innovaciones que en todos los órdenes del saber y de la producción se presentaban en los recintos expositivos con el fin de aplicarlas en sus países de origen. El mexicano Pedro Escandón, en la memoria que dirigió al ministro de Fomento sobre la exposición parisina de 1855, insistió en diversas recomendacio-

\footnotetext{
expositions françaises de la seconde moitié du XIXème siècle", comunicación presentada en el simposio Mondialization of science: between colonial enterprise and national project (1870-1960), organizado por P. Petitjean y D. Kumar en el marco del XX Congreso Internacional de Historia de la Ciencia celebrado en Lieja del 20 al 26 de julio de 1997 y en "Tentáculos del progreso. La América latina en el escenario de las exposiciones universales del siglo XIX", conferencia presentada en el Coloquio "O Mundo IberoAmericano nas Grandes Exposiçoes", celebrado en la Sociedad de Geografia de Lisboa el 4 y 5 de junio de 1998. Las actas de ambos eventos académicos se publicarán próximamente.

49 Datos tomados de IOB, “Crónicas de la Exposición de Paris", La Ilustración Española y Americana, año 1889, vol. II, pp. 199-203.
} 
nes ${ }^{50}$. Por ejemplo, al dar cuenta del desarrollo experimentado por el uso de las plantas filamentosas o textiles - como el lino y el cáñamo- en sus aplicaciones industriales para la marina o la papelería, aconsejó la aclimatación de algunas de ellas en territorio mexicano, o el incremento del cultivo de plantas autóctonas, como el henequén de Yucatán. De hecho, después de esas recomendaciones de Escandón el cultivo del henequén en la península de Yucatán experimentó un auge considerable. Si en 1840 su exportación fue de mil toneladas, en la segunda mitad del siglo XIX alcanzó las veinte mil toneladas anuales, que suponían el $15 \%$ del total del valor de las exportaciones mexicanas. El incremento del área de cultivo de ese producto entre 1860 y 1878 fue posible gracias a dos innovaciones técnicas: la utilización de la desfibradora inventada por José Esteban Solís, y la introducción en 1861 de las máquinas de vapor.

A su vez los latinoamericanos implicados en la organización de las exposiciones universales usaron estas como escaparates de los progresos que en todos los órdenes de la vida material y cultural estaban experimentando sus sociedades. Los promotores y expositores de los pabellones latinoamericanos presentaron a la América latina como una tierra de promisión para capitales y emigrantes foráneos por su exuberante naturaleza y sus abundantes materias primas. Expusieron también la riqueza de un patrimonio cultural propio, producto de su densidad histórica, y exhibieron finalmente la capacidad creativa de sus habitantes en las artes y las ciencias.

Esa pluralidad de intenciones y mezcolanza de imágenes se percibe, por ejemplo, en la organización de la sección argentina de la fachada común que se otorgó a los diez países que representaron a la América latina en la calle de las Naciones de la Exposición de Paris de $1878^{51}$.

Al entrar el visitante quedaba abrumado por una serie de estadísticas y paneles que ofrecían abundante información sobre la demografía, la economía, las telecomunicaciones, el sistema educativo y científico de la República Argentina. En la sección mineralógica se podía contemplar magníficas colecciones de fósiles, como las formadas por el fundador de la paleontología argentina Ameghino y por otros naturalistas amateurs, con fondos procedentes de los riquísimos yacimientos existentes en la Mesopotamia argentina y en las pampas. Y asimismo podía examinar diversas manifestaciones de la ordenación del territorio que estaban llevando a cabo los argentinos, y un haz de sus producciones culturales. Por ejemplo, una serie de planos del Castillo del Agua de Buenos Aires, cuya construcción se había iniciado en 1869, así como un folleto, explicaban cómo esa obra de ingeniería intentó resolver el problema de la conducción y distribución de agua potable, y revelaban las tareas de

\footnotetext{
50 EsCandon, P. (1856), La Industria y las Bellas Artes en la Exposición Universal de 1855. Memoria dirijida al Excelentísimo señor Ministro de Fomento de México por Pedro Escandón, Paris.

51 Ver LAMARRE, CL. y WIENER, Ch., (1878), L'Amérique centrale et méridionale et l'exposition de 1878, Paris, pp. 151-196.
} 


\section{LEONCIO LÓPEZ-OCÓN CABRERA}

saneamiento emprendidas tras las epidemias de cólera de 1865 y de fiebre amarilla en 1870.

Esa doble pretensión de las élites latinoamericanas de usar las exposiciones universales como escuelas de aprendizaje de la civilización industrial y como escaparates de sus progresos muestra que los objetos científicos y técnicos expuestos en ellas, tras circular internacionalmente, lograron tener una cierta recepción social debido a la tarea proselitista desplegada en pro del desarrollo de una mentalidad cientificista durante la era del positivismo a través de la creación de múltiples redes de popularización, en las que participaron científicos, tecnólogos y educadores.

Curiosamente dos iniciativas culturales surgidas en los Estados Unidos, relacionadas con la participación latinoamericana en la Exposición Universal de Paris de 1889 , nos indicarían que desde el exterior se veía ya en esa época la existencia de un incipiente espacio público para la ciencia en la América latina.

En 1889 José Martí creó en Nueva York, gracias a la ayuda financiera del brasileño Da Costa Gómez, una efímera revista infantil: La Edad de Oro. Destinada a los niños americanos, en sus cuatro números se publicaron tres largos artículos y numerosas ilustraciones sobre esa exposición universal. Al presentar tal evento como un gigantesco tiovivo de la naturaleza y un enorme calidoscopio de la pluralidad de las culturas humanas, Martí pretendía despertar en sus particulares lectores una atención y un asombro no sólo ante las maravillas de la sociedad industrial, sino también ante la riqueza y variedad de las sociedades humanas y la complejidad de la historia que la habían hecho posible 52 .

Meses después, en enero de 1890, en la misma ciudad de Nueva York se presentó al público con el título de La América científica e industrial la edición española de la revista neoyorquina Scientific american, dirigida al mundo americano de habla española. Sus editores parecían ser conscientes de dos hechos: de que ya existía un espacio público para la ciencia y la tecnología en la América latina, y de que los Estados Unidos estaban ya en condiciones de disputar la hegemonía cultural y económica que hasta entonces había ejercido Europa en esa región del mundo. Y es por ello por lo que los primeros números de esa publicación establecieron un hilo de continuidad entre la exposición de Paris y la de Chicago. Tras presentar a sus lectores los pabellones de las repúblicas hispanoamericanas en la exposición parisina de 1899, y dar cuenta del impacto que tuvieron en ella algunos inventos de Edison como el fonógrafo, enseguida se dedicó a hacer una constante propaganda y un panegírico de la exposición universal de Chicago con la que se consolidó la atracción de la ciencia y la tecnología norteamericana sobre el resto de las Américas.

52 Existe una reedición reciente, MARTI, J, (1990), La edad de oro, Madrid, con introducción de Gaston Baquero. Ver también AlmENDROS, H. (1956), A propósito de "La edad de oro" de José Martí. Notas sobre literatura infantil, Santiago de Cuba. 


\section{CONCLUSIONES}

El proceso de creación de un espacio público para la ciencia que se construyó en la América latina durante el siglo XIX tuvo un movimiento ascendente, tal y como se ha podido constatar por quienes han estudiado los esfuerzos divulgativos realizados en la prensa periódica latinoamericana en general, y mexicana en particular. Se observa una fase inicial de construcción de un interés por la divulgación científicotécnica en la prensa ilustrada, continuada por una etapa de díficil consolidación de esos instrumentos de divulgación durante el período romántico, y proseguida por un movimiento de esplendor de la divulgación científico-técnica en los periódicos del "movimiento cientificista" del período positivista, que se plasmó en una mayor proliferación y densidad espacio-temporal de esas empresas publicitarias.

Ahora bien, teniendo en cuenta el alto grado de analfabetismo de las sociedades latinoamericanas del siglo XIX, formadas, como ha expresado el historiador brasileño José Murilo de Carvalho, por "islas de letrados en un mar de analfabetos" 53 , el radio de acción e influencia de los instrumentos impresos de divulgación fue forzosamente limitado, alcanzando fundamentalmente a las incipientes clases medias urbanas.

Por esta razón, si bien cabe comprobar la existencia de un incipiente espacio público para la ciencia en la América latina construido en torno a la proliferación de iniciativas divulgativas a través de la prensa, la labor pedagógica de los museos, las actividades de extensión cultural de las sociedades científicas y la participación latinoamericana en las exposiciones universales, también hay que tomar en consideración las estrecheces y limitaciones de ese espacio en el que se producía la interacción entre una oferta y una demanda de conocimientos científico-técnicos, de la que se ha dado cuenta. La ciencia y la tecnología en América latina eran, al empezar el siglo $\mathrm{XX}$, frágiles.

Y. esa fragilidad, como es bien sabido, continúa en la actualidad, como lo revelan las siguientes cifras: mientras que en 1995 la América latina sólo gastaba cuatro mil millones de dólares en investigación, los Estados Unidos y la Unión Europea gastaban respectivamente 124.000 y 104.000 millones de dólares, lo que se traduce en que en esa región del mundo, con una población total similar a la de Europa occidental, se produce 20 veces menos ciencia que en la Unión Europea con un potencial de científicos cuatro veces menor.

53 Ver al respecto GoldFarb, A.M.A., MEndes Ferraz, M.H. y FigueiroA, S.F. de. M. (1997), "Diffuser les sciences 'dans un océan d'analphabétisme': singularités brésiliennes", en BENSAUDE-VINCENT, B. y RASMUSSEN, A. (1997), eds., La science populaire dans la presse et l'édition, Paris, pp. 225-236 